computerised, stored, and retrieved as required for research and administrative purposes. The need for objective scientific evaluation of such systems, and their constituent items, is emphasised by our findings. Such practice allows identification of poorreliability items, and subsequent revision of their definitions. The appropriateness of item sheets for the particular patient group under study always requires evaluation. Ultimately, the reliability and

\section{References}

${ }^{1}$ Hill, D., BiRley, J. L. T., Cawley, R. H., Kendell, R. E., Lishman, W. A., Post, F., Rutter, M., Wing, J. K. \& WolfF, H. H. (1973) Notes on Eliciting and Recording Clinical Information. Oxford University Press.

${ }^{2}$ Kendell, R. E. \& Gourlay, J. (1970) The clinical distinction between psychotic and neurotic depression. British Journal of Psychiatry, 117, 257-260.

${ }^{3}$ SHUR, E. (1982) Season of birth in high and low genetic risk schizophrenia. British Journal of Psychiatry, 140, 410-415.

${ }^{4}$ Grosz, H. J. \& Grossman, K. G. (1964) The sources of observer variation and bias in clinical judgments, Journal of Nervous and Mental Disease, 138, 105-113. usefulness of any data collected remains dependent on the skill and conscientiousness of the individual who completes the ratings.

This small-scale assessment study suggests that this approach to rapid coding of standardised information not only provides reliable data but also introduces a useful aide-memoire and an instructive intellectual training exercise for the aspiring psychiatrist in his everyday ward work.

5 (1968) The relationship between neurosis and psychosis, British Journal of Psychiatry, 114, 189-192.

${ }^{6}$ Wing, J. K., COOPER, J. E. \& SARTORIUS, N. (1974) The Measurement and Classification of Psychiatric Symptoms, London: Cambridge University Press.

${ }^{7}$ Ciccherti, D. V. (1978) Assessing observer and method variability in medicine. Connecticut Medicine, 42, 253-256.

${ }^{8}$ ThORLeY, G. (1982) The Bethlem Royal \& Maudsley Hospitals Clinical Data Register for Children and Adolescents. Journal of Adolescence, 5, 179-190.

\title{
A service for patients with Wilson's disease
}

\author{
T. R. Dening, Research Fellow, Department of Psychiatry; G. E. BerRios, Consultant \\ and University Lecturer in Psychiatry; and C. A. SEYMOUR, Consultant and University \\ Lecturer in Medicine, University of Cambridge Clinical School
}

Wilson's disease (WD) is an autosomal recessive disorder of copper metabolism with an incidence of about 30 per million (i.e. fewer than 2,000 in the UK). Nevertheless, it is important for two main reasons: its manifestations are protean and may lead it to present to a range of specialists; and its otherwise lethal course can be halted by treatment with chelating agents such as penicillamine and trientine. Published cases $^{1}$ and systematic study ${ }^{2}$ have shown that neuropsychiatric symptomatology is important in a high proportion. In fact, about one-fifth either present psychiatrically or are at least seen by a psychiatrist before WD is diagnosed.

Addenbrooke's Hospital, Cambridge has been the centre for the largest series of WD in the UK (over 200 cases) due to the presence of Dr John Walshe, who was responsible for the initial introduction of penicillamine $^{3}$ and other agents, as well as many clinical and laboratory studies of WD and copper metabolism. In September 1987 JMW retired, and the responsibility for WD passed to CAS. The aim of this paper is to describe the workings of the service until Autumn 1987, with particular respect to psychiatric aspects, and then to discuss future developments.

The service as operated by JMW, Reader in Metabolic Diseases and Consultant Physician, included clinical and laboratory components. All copper biochemistry was performed in a laboratory in the Department of Medicine. Junior medical staff were shared with the rest of the academic unit, but only involved with in-patients. All referrals, including 
those from overseas, were accepted. Up to four or five beds were available for cases of WD on the acute medical ward. Such beds were occupied by severely ill patients treated intensively for as long as necessary (over one year if required) in view of the difficulty of predicting the degree of likely recovery. Other (less ill) cases could be admitted to the ward for a few days for assessment, or else accommodated in the hospital's rehabilitation hostel, or seen as out-patients whilst staying in local bed and breakfasts. Follow-up arrangements were similar, but, as patients were usually better at follow-up, more were seen as outpatients. Most patients attending for follow-up were also under medical (or neurological) care in their own locality, others supervised by their GPs. The followup interval for the Cambridge clinic was one to two years in patients doing well, more often if difficulties were encountered.

Contact with the University Department of Psychiatry began soon after the inception of the Cambridge Clinical School in 1977. It was as registrar on the Professional Unit that TRD saw his first case and began to develop an interest. At first the psychiatrist was only involved with cases posing management problems e.g. overdoses, hypomanic episodes, severe behavioural disturbances. Gradually, as it became clear that we were genuinely interested and that our assessments could be of benefit, we began to see less disturbed individuals. For the last 18 months TRD has been engaged as a full-time Research Fellow studying psychiatric aspects of WD, and during this time all English-speaking patients were seen for the purposes of research as well as clinical assessment. Several non English-speakers (usually Italians of Greeks) were interviewed through interpreters when the need arose.

A feature of the service was the high rate of consultation with other specialties-ophthalmology routinely; also radiology, general surgery, orthopaedics, anaesthetics and intensive care, oral surgery and orthodontics, obstetrics and gynaecology all being commonly involved, with the physician taking overall responsibility and supervising treatment of the WD. Other non-medical professionals, especially clinical psychologists and speech therapists, made frequent and valuable contributions. The effect of such wide referral within the hospital has been to create considerable local expertise. It was felt, that despite the departure of the central figure, it would be wasteful and not in the best interests of the patients to dismantle such a concentration of experience of problems related to WD.

Future arrangements will therefore be developed from this foundation with emphasis on a team approach, recognising the multi-system problems posed by the disease. Again, administrative charge will lie with a physician (CAS), and a network of consultants will provide specialist input. It is envisaged that initially the number of patients will be rather less, with some having made alternative local arrangements. The physician will not be working full-time with WD, but sees herself as the coordinator of the team. Psychiatrists will be core members of this team, providing assessments routinely and taking on the management of cases with profound disorders. For assessment, use will be made of a locally-developed battery of neurological, psychiatric and neuropsychological instruments which has already been used to gather data in a prospective manner (Dening \& Berrios, in preparation). Beds on the Professorial Unit, Fulbourn Hospital will be available for disturbed individuals when required.

Although the primary purpose of any clinical service is to promote good patient care, such a resource also has a responsibility for research and training. Patients with WD are invaluable teaching material for undergraduates and provide excellent insights into neuropsychiatry for psychiatric trainees. Research is proceeding in the same collaborative vein: it is hoped, for example, to study the relationship between cognitive function and Magnetic Resonance Imaging in WD.

The continuing service is operational, and will willingly accept new referrals or discuss established cases.

\section{References}

${ }^{1}$ Dening, T. R. (1985) Psychiatric aspects of Wilson's disease. British Journal of Psychiatry, 146, 677-682.

2 _- BerRios, G. E. \& WALSHE, J. M. (1988) Wilson's disease and epilepsy. Brain, 111, 1161-1177.

${ }^{3}$ WALSHE, J. M. (1956) Penicillamine, a new oral therapy for Wilson's disease. American Journal of Medicine, 21, 487-495. 